\title{
PBL COMO METODOLOGIA DE ENSINO DE FONOAUDIOLOGIA UMA EXPERIÊNCIA PIONEIRA
}

\author{
Livia Miranda de Oliveira é graduada em Fonoaudiologia pela Universidade Federal do Rio de Janeiro (UFRJ), Mestre em \\ Linguística pela Universidade Federal de Juiz de Fora (UFJF), Doutoranda em Estudos da Linguagem pela Pontifícia Universidade \\ Católica do Rio de Janeiro (PUC-Rio), bolsista de doutorado do CNPq (Proc. 140984/2010-0), Professora do Núcleo de \\ Fonoaudiologia da Universidade Federal de Sergipe (UFS) \\ E-mail: liviamiranda@gmail.com
}

Fabiana Cristina Carlino é graduada em Fonoaudiologia pela Faculdade de Odontologia de Bauru (FOB/USP), Mestre e Doutora em Educação Especial pela Universidade Federal de São Carlos (UFSCar), Professora do Núcleo de Fonoaudiologia da Universidade Federal de Sergipe (UFS).

Mônika Miranda de Oliveira é graduada em Fonoaudiologia pela Universidade Federal do Rio de Janeiro (UFRJ), Mestre em Linguística pela Universidade Federal de Juiz de Fora (UFJF), Professora do Núcleo de Fonoaudiologia da Universidade Federal de Sergipe (UFS).

Iara Maria Ferreira Santos é graduada em Fonoaudiologia pela Universidade Federal de Sergipe (UFS), Especialista em Psicopedagogia Institucional pelo Centro Integrado de Tecnologia e Pesquisa (CINTEP), vinculado à Faculdade Nossa Senhora de Lourdes, Professora do Núcleo de Fonoaudiologia da Universidade Federal de Sergipe (UFS).

\section{Resumo}

Este relato de experiência busca retratar a vivência de situações de ensino-aprendizagem no curso de fonoaudiologia da Universidade Federal de Sergipe (campus de Ciências Médicas de Lagarto), que adota o PBL (Problem Based Learning) como metodologia exclusiva de ensino. A disciplina "Linguagem na Infância e Adolescência" foi selecionada para relato da experiência de ensino de fonoaudiologia por meio do PBL. O texto foi estruturado de modo a apresentar as vivências de diferentes momentos de uso dessa metodologia ativa: 1. Iniciou-se pelas sessões tutoriais, que fundamenta e sustenta teoricamente todas as outras práticas; 2. Prosseguiu-se com as práticas de habilidades, que consiste em observar e treinar avaliação, diagnóstico e procedimentos terapêuticos; e 3. Finalizou-se com as práticas de ensino na comunidade (PEC), que é o momento em que os alunos entram em contato direto com a realidade de diferentes campos de atuação. Pôde-se observar que o PBL apresenta diversas vantagens, tais como o fato de contribuir sobremaneira para a formação de fonoaudiólogos autônomos, seguros de suas práticas clínicas devido à imersão precoce no contexto da prática. Todavia, destacam-se também nossos conflitos e inquietações enquanto professoras, diante da necessidade que sentimos de nos servir de momentos de instrução expositiva, dada a complexidade dos assuntos e interfaces contempladas na disciplina em questão.

\section{Abstract}

This experience report portrayed teaching-learning situations on Speech, Language and Hearing Science undergraduate course at Lagarto Medical Studies Campus of Federal University of Sergipe, which adopts PBL (Problem Based Learning) as exclusive learning method. The discipline "Speech on Childhood and Adolescence" was selected for relating this experience on teaching Speech, Language and Hearing Science by PBL method. The text was structured to show the experience of different moments of active methodology use: 1 . It was started by tutorial sessions, which base and sustain theoretically all other practices; 2 . It continued with the practice of "skills", which consists to observe and to train evaluation, diagnostic and therapeutic procedures; 3 . It finished with teaching practices in the community, when students come into direct contact with the reality of different fields. It was observed that the PBL has several advantages, such as the fact that it highly contributes to the formation of autonomous professionals, confidents of their clinical practice due to early immersion in practical context. However, our conflicts and anxieties as teachers are highlighted on the need we feel to have moments of expositive instruction, due to the complexity of issues and interfaces included in this discipline 


\section{Introdução}

O ensino das profissões de saúde, habitualmente, tem se fundamentado na presunção de que o domínio e transmissão de conhecimento e habilidades, lastreados nos últimos avanços técnico-científicos, conduzem necessariamente a uma prática profissional adequada. Organizam-se os currículos privilegiando-se a aquisição de bagagem cognitiva, psicomotora e, em menor extensão, afetiva. A concepção hegemônica de assistência à saúde ainda é a centrada no médico e no hospital. Em geral, as práticas a partir das quais são realizados os "treinamentos" constituem simulação do trabalho profissional, pois, apesar de envolver personagens reais (profissionais e pacientes), desenrolam-se em condições e cenários muito distintos daqueles encontrados nas situações de trabalho concretas.

Há, com certeza, muitas metodologias de ensino-aprendizagem que podem ser utilizadas para promover uma aproximação do aluno à realidade com a qual ele irá se deparar em seu futuro profissional. De certo modo, metodologias ativas e/ou colaborativas de ensino-aprendizagem, centradas nos alunos, atendem a esse propósito. Entre as diversas metodologias, encontra-se a Aprendizagem Baseada em Problemas, ou PBL (Problem-Based Learning), como é comumente conhecida. O PBL contempla fundamentos e procedimentos subsidiados por teorias construtivistas, sendo reconhecido por gerar possibilidades de se trabalhar simultaneamente conceitos, habilidades e atitudes em atividades que se passam fora e dentro da sala de aula, sem a necessidade de as disciplinas serem concebidas especialmente para esse fim (Savin-Baden, 2000). Ademais, ao contrário dos métodos convencionais de ensino, cuja noção de competência está fortemente baseada no conteúdo, no PBL entende-se competência profissional como a capacidade de fazer julgamentos informados sobre o que é problemático em uma dada situação, saber identificar os problemas mais relevantes e saber como resolvê-los ou, ao menos, melhorar a situação (Margetson, 1999).

Originado na escola de medicina da Universidade McMaster, no Canadá, em meados dos anos 1960, o PBL é essencialmente uma metodologia de ensinoaprendizagem que utiliza problemas da vida real (reais ou simulados) para iniciar, enfocar e motivar a aprendizagem de teorias, habilidades e atitudes. O PBL, assim como outros métodos construtivistas, está pautado no pressuposto de que o conhecimento é construído em vez de simplesmente memorizado e acumulado. Além disso, o PBL fundamenta-se em resultados de pesquisas educacionais, especialmente na área da psicologia cognitiva, que indicam que o trabalho dos alunos com a vida real, particularmente em grupos, favorece a aprendizagem, em outras palavras, o contato com a realidade, a prática contextualizada, favorece a aprendizagem.

A adoção do PBL é justificada por seus idealizadores como uma resposta à percepção dos professores de que os alunos estavam saindo do curso com muitos conceitos, mas pouca capacidade de utilizá-los e integrá-los à prática cotidiana (Barrows, 1996). Esses efeitos do ensino tradicional são corroborados por muitos 
educadores que posteriormente adotaram o PBL em seus cursos de medicina (Lipkin, 1989). Para eles, o modelo tradicional tornava os alunos mais passivos, menos questionadores, mais submissos à autoridade e menos criativos. Os alunos não se dedicavam à aprendizagem contínua, apesar da rápida obsolescência dos conhecimentos aprendidos durante a formação; subutilizavam os conhecimentos humanísticos e suas habilidades interpessoais; regrediam, tornando-se assim mais autoritários.

A característica mais importante no PBL é o fato de uma situação-problema sempre preceder a apresentação dos conceitos necessários para sua solução. Ou seja, a principal característica que difere o PBL de outros métodos ativos, colaborativos, centrados nos alunos, no processo e da aprendizagem baseada em casos (CBL) é o emprego de problemas para iniciar, enfocar e motivar a aprendizagem de conteúdos específicos e para promover o desenvolvimento de habilidades e atitudes profissional e socialmente desejáveis. A colocação de desafios na forma de problemas relevantes à futura atuação dos alunos antes da apresentação da teoria é considerada por Barrows como "o núcleo absolutamente irredutível da aprendizagem baseada em problemas" (Barrows, 1996, p. 7).

Os problemas no PBL devem ser reais ou potencialmente reais e envolver, explícita ou implicitamente, muitas das variáveis sociais e ambientais inerentes ao contexto profissional real. No entanto, apesar de sua similaridade com os problemas da vida real, os problemas no PBL devem ser condizentes com o nível cognitivo/motor/afetivo dos alunos. Isto é, devem ser concebidos de forma a desafiar a capacidade intelectual/emocional e a destreza dos alunos, mas sem frustrar sua capacidade de resolvê-los. Ademais, o problema no PBL deve sempre gerar um produto concreto, o que facilita sua apreciação pelos próprios alunos. Talvez, a característica mais importante do problema PBL seja sua fraca estruturação, isto é, quando não determina um caminho único de investigação. Como ocorre na prática profissional, no PBL os alunos não devem ter todas as informações relevantes e tampouco conhecer as ações necessárias para sua solução. Quanto maior a ambiguidade, maior a oportunidade de os alunos se engajarem em um processo reiterativo de reflexão, definição, coleta de informações, análise e redefinição do problema, e de desenvolverem habilidades de solução de problemas e/ ou estudo autônomo.

O curso de Fonoaudiologia da UFS do Campus Lagarto é o primeiro no país a utilizar o PBL como metodologia exclusiva de ensino-aprendizagem na fonoaudiologia, o que justifica nossa pretensão (e a real necessidade) de mostrar como essa proposta vem sendo aplicada. Portanto, neste relato de experiência, traremos ao conhecimento do leitor o funcionamento do PBL nessa instituição (UFS, campus Lagarto), onde somos docentes, elucidando as vivências de ensino de fonoaudiologia, na disciplina Linguagem na Infância e Adolescência. Em um primeiro momento, descreveremos nossas experiências com as sessões tutoriais, o locus reservado para um aprofundamento teórico que fundamente a prática. Posteriormente, compartilharemos as 
experiências das práticas de habilidades, e, por fim, das práticas de ensino na comunidade (PEC).

\section{1) Sessões Tutoriais}

Assumir a posição de tutora foi uma experiência um tanto exótica pra nós, que somos formadas pelo método tradicional de ensino e que, sobretudo, vislumbramos ensinar, ao invés de mediar processos de construção de conhecimentos em uma ruptura da dicotomia transmissão versus recepção de conhecimentos, a favor da emergência de uma estrutura de permuta que contempla a construção conjunta e colaborativa do conhecimento. Essa posição nada familiar implicava em posturas até então desconhecidas para nós (não enquanto fonoaudiólogas, mas sim enquanto professoras, ou seja, no contexto de sala de aula), como, por exemplo, repassar o pincel e a lousa para o aluno e ser "mais um" no círculo de cadeiras das sessões de tutorial, na tentativa de tornar as interações mais simétricas possíveis em termos de poder.

Concordando com a tese foucaultiana de que o poder está em todo lugar (cf. Foucault, 1978), ali naquele cenário, a tentativa era que assimetrias de poder fossem diluídas em prol da autonomia dos alunos, ou melhor, da formação de profissionais autônomos e com capacidade de reflexão. Todavia, o que mais gerava um desconforto para nós, tutoras, não era a ratificação do poder dos alunos, mas sim a angústia de querer passar conhecimentos e ser impossibilitadas disso pela metodologia que operava naquelas sessões de tutoriais, em que o discurso do professor cede lugar ao discurso do aluno, em uma reversibilidade de papéis - o aluno assume o papel de falante e o tutor o papel de ouvinte/ interlocutor - e, nessas trocas discursivas, os alunos assumem o controle da interação, alocados como participantes ativamente engajados nas discussões, coordenadores e secretários das sessões.

As sessões tutoriais aconteciam às terças-feiras (abertura da situação-problema) e sextas-feiras (fechamento da situação-problema), com duração de quatro horas e trinta minutos. No início de cada sessão tutorial, acontecia a eleição de um aluno-secretário, que era o responsável por anotar na lousa termos desconhecidos pelo grupo, que constavam na situação-problema, perguntas que direcionavam as discussões pautadas em conhecimentos prévios e, por fim, os objetivos levantados pelo grupo, que iriam guiar os estudos individuais posteriores; e de um aluno-coordenador, cuja responsabilidade consistia, sumariamente, em coordenar as discussões do grupo, estimulando a participação de todos os colegas do grupo na discussão do problema. Os demais alunos eram incumbidos a se engajarem ativamente nas discussões em curso a todo o momento, pois suas participações eram avaliadas pelo tutor a cada encerramento de sessão.

Após os próprios alunos elegerem seus colegas para secretário e coordenador, iniciava-se a abertura das situações-problema, as quais motivavam a aprendizagem. $\mathrm{O}$ 
secretário lia o problema a ser discutido pelos alunos com base em seus conhecimentos prévios e as discussões tinham início com a mediação do tutor. Apenas breves intervenções de caráter incentivador (e também direcionador) nos eram autorizadas, de modo que conhecimentos por nós adquiridos ao longo de anos de estudos e pesquisas acerca dos assuntos abordados não poderiam ser expostos/transmitidos aos alunos, que deveriam chegar a tais conhecimentos por eles próprios, apenas por nossas ações mediadoras e por suas buscas por referências bibliográficas.

Os problemas eram previamente elaborados pelos professores do curso e reunidos em um módulo (o módulo de linguagem continha 10 problemas), e sempre abordavam questões referentes às disciplinas do curso de fonoaudiologia, por meio de histórias que enquadravam tais questões em um contexto cotidiano que se aproximava da vivência pessoal dos alunos. No caso do módulo cujas experiências proporcionadas estão sendo aqui apresentadas, foram tratadas temáticas referentes às patologias da linguagem na infância, atendendo à grade curricular dos cursos de fonoaudiologia do Brasil.

Sendo a linguagem um fenômeno um tanto complexo, apresentá-la, bem como as suas patologias, aos alunos, implicava em alçar interfaces tanto com as ciências humanas, mais precisamente a linguística e a psicologia, como também com as ciências da saúde, mais precisamente a neurologia. Portanto, essa costura necessária e indispensável de conhecimentos advindos de diferentes áreas do saber tornava os encontros tutoriais ainda mais desafiadores. Nós, tutoras, em nossas mediações, deveríamos conduzir os alunos a alcançarem os objetivos propostos para cada problema, e, em se tratando do módulo de linguagem, tais objetivos não podiam ser simplistas, dada a grandiosidade das referidas interfaces, pois para atuar clinicamente em casos de linguagem, o fonoaudiólogo precisa conhecer a linguagem de seu paciente, tanto em suas faces linguísticas (os níveis linguísticos), como em suas faces neurológicas (o processamento cerebral da linguagem). Não havia lugar para conhecimentos superficiais acerca desse híbrido objeto de estudo - a linguagem. Diante disso, um questionamento que sempre nos fazíamos era como conduzir os alunos a fazer interfaces de assuntos complexos e por eles desconhecidos. Era muito conteúdo, conceitos de diferentes áreas, que deveriam ser alinhavados em pouco tempo, e por quem estava tendo o primeiro contato com a linguagem, a linguística, a psicologia e a neurologia.

Diante de problemas que abordavam relatos de casos clínicos de patologias da linguagem, cabiam aos alunos reflexões i) que tratassem da histologia, anatomia e fisiologia do Sistema Nervoso Central (SNC), da linguística e seus níveis (fonética, fonologia, morfologia, sintaxe, semântica e pragmática), das teorias linguísticas e psicológicas de aquisição e desenvolvimento da linguagem, bem como da articulação da neurologia com a linguística, sem alocar à parte os fatores socioculturais, e ii) que possibilitassem compreender as patologias apresentadas em cada problema. Tais metas não eram explicitadas para os alunos, que, por nossos direcionamentos, deveriam 
levantar objetivos de aprendizagem que conduzissem ao aprofundamento teórico, com base apenas na situação-problema (como, por exemplo, relatos de casos clínicos), a fim de terem em mãos um roteiro para estudo, pois no fechamento de cada problema, as discussões giravam em torno daquilo que os alunos abordaram em seus estudos individuais autodirigidos.

O estudo autodirigido é tomado, no PBL, como parte integrante e contínua do processo de aprendizagem. $\mathrm{O}$ aluno tem, mais uma vez, a possibilidade de exercer o papel de sujeito ativo nas relações de ensino-aprendizagem, tendo possibilidade, também, de reconhecer-se numa relação de alteridade e emancipação. No caso dos estudos individuais, entretanto, os alunos encontraram alguns problemas no que concerne ao acervo bibliográfico. Como se trata de um curso em formação, grande parte dos livros a serem utilizados pelos alunos da fonoaudiologia ainda estavam sendo comprados. No entanto, essa questão não consistiu em fator impeditivo para o estudo individual autodirigido, de modo que os alunos conseguiram driblar essa dificuldade com êxito, recorrendo a outras fontes. Tal êxito pôde ser verificado pelos fechamentos dos problemas, pois esta etapa está ligada à formulação dos objetivos e, sobretudo, ao estudo individual. Rediscutia-se no grupo tutorial, então, os avanços de conhecimentos obtidos pelo grupo.

Em suma, para cada situação-problema havia três momentos - a abertura, o estudo autodirigido e o fechamento. A abertura acontecia em uma primeira sessão; o estudo autodirigido era realizado em casa (e os alunos tinham dois dias para isso); e o fechamento do problema acontecia em uma sessão posterior. A sessão de fechamento se iniciava com a leitura, por parte do coordenador, dos objetivos de estudo estabelecidos na sessão anterior (de abertura). Os alunos eram, então, estimulados pelo alunocoordenador a discutir o tema levantado, trazendo embasamentos científicos e correlacionando os conhecimentos construídos com suas vivências na PEC e em habilidades, bem como levantando seus questionamentos.

As situações-problema de linguagem permitiam aos alunos o encontro com uma variedade grande de autores e perspectivas teóricas. Desse modo, as sessões foram bastante ricas em termos da diversidade de literatura consultada. Por outro lado, houve momentos nos quais o tempo não foi suficiente para garantir a continuidade das discussões, as quais iam ganhando novas costuras e questionamentos. Todavia, a metodologia adotada permitia que as discussões fossem retomadas em momentos posteriores, nos encontros de habilidades e PEC, pois essas três subunidades - tutorial, habilidades e PEC - caminham paralelamente.

Nossa inquietação nas sessões tutoriais era, sobretudo, não poder oferecer os fundamentos para, então, os alunos construírem suas reflexões, articulando interfaces. Todos fundamentos eram por eles buscados com base nos objetivos que eles levantavam, que foram por nós autorizados e que se constituíam no roteiro de estudos. Silenciar-se diante de alunos sedentos por aprender, e tendo as respostas que eles 
requeriam, era, de fato, uma árdua tarefa. Apenas a confiança na grande possibilidade de sucesso da aplicação do PBL como metodologia de ensino de fonoaudiologia nos tornava um pouco mais conformadas. Trata-se de uma possibilidade de sucesso porque, embora o PBL já venha sendo utilizado em reconhecidas universidades nacionais e internacionais desde 1960, o curso de fonoaudiologia da UFS-Lagarto foi o primeiro a adotar o uso exclusivo dessa metodologia na formação de profissionais fonoaudiólogos.

No entanto, índices da efetividade dessa metodologia surgiam a cada encerramento de problemas nas sessões tutoriais, pois, após um período de estudo (que se estendia da abertura do problema, terça-feira, ao encerramento do problema, sextafeira), os alunos retornavam às sessões tutoriais com discussões produtivas e que demonstravam terem sido frutos de estudos aprofundados, de buscas ativa pelo saber, logo, de um comprometimento com a própria formação profissional. Assim sendo, nossa maior satisfação era observar os alunos desvendarem as patologias da linguagem, seus sinais e sintomas, sua etiologia, entre outros aspectos, de modo autônomo, descobrindo, por meio de pesquisas por literatura e leituras, tudo aquilo que não foi passado para eles por meios expositivos. Dos encerramentos/fechamentos dos problemas vinha o estímulo para prosseguir, ou seja, o incentivo necessário para acreditarmos que rupturas paradigmáticas no contexto de ensino-aprendizagem podem trazer bons frutos se aqueles que estiverem engajados ativamente nessa ruptura - alunos e tutores - cumprirem fidedignamente os papéis a eles designados.

Por outro lado, torna-se relevante destacar que nem todos os alunos se adaptaram ao PBL, assim como também acontece quando a metodologia assumida é a tradicional. Porém, como ainda estamos no segundo ciclo (o que corresponde ao segundo ano), nenhuma consideração pode ser conclusiva, visto que os alunos ainda terão tempo para melhor aceitar a mudança que está se estabelecendo, de modo que muitas críticas atuais (da parte dos alunos) possam ceder lugar ao reconhecimento de que o PBL, se levado à sério, pode contribuir para a formação de profissionais autônomos e com ampla capacidade de reflexão crítica e de atuação profissional madura; afinal, por meio de uma formação profissional que integra teoria à prática, essa metodologia i) coloca o aluno em contato com a realidade profissional desde o primeiro ano, ii) possibilita a superação de requisitos teóricos para se partir para a prática, iii) promove a aprendizagem do conhecimento de forma não necessariamente lógica e sequencial; e iv) favorece a responsabilização dos alunos pelo seu desenvolvimento profissional e comportamento ético em relação aos colegas, professores, profissão e sociedade (Ribeiro, 2010). No que diz respeito à integração da teoria à prática, a proposta é que esta seja garantida por três pilares - as sessões tutorias, cujas experiências proporcionadas acabamos de relatar, as aulas de habilidades e a prática de ensino em comunidade, que serão abordadas a seguir.

\section{2) Práticas de Habilidades}


Os encontros de habilidades aconteciam às segundas-feiras, com duração de seis horas, e tinham a finalidade de integrar a teoria aprendida nas sessões tutoriais à prática. No caso da disciplina cuja experiência está sendo aqui relatada - Linguagem na Infância e Adolescência - nos encontros de habilidades, eram apresentados aos alunos ferramentas para a prática da intervenção clínica em casos de patologias da linguagem.

Durante os encontros de habilidades, o aluno tinha a possibilidade de vivenciar a elaboração e aplicação de instrumentos de avaliação na área de linguagem, ao mesmo tempo em que sua capacidade criativa era estimulada, por meio, por exemplo, de construção de jogos e materiais que sirvam tanto para a avaliação quanto para a intervenção, logo, para a prática clínica fonoaudiológica. As atividades desenvolvidas em habilidades eram realizadas em paralelo com as sessões tutoriais, a fim de proporcionar uma relação da teoria com a prática, e, ao mesmo tempo, propiciar um ambiente para que o conhecimento recém-construído (de forma colaborativa, nas sessões tutoriais, e de forma autônoma, nos estudos individuais) fundamentasse o treino da prática, preparando o aluno para atuação clínica.

Nas primeiras duas horas dos encontros de habilidades, os alunos participavam de o que pode ser considerado casos de ensino baseados em palestras (cf. Ribeiro, 2010), em que apresentávamos conteúdos que complementavam as sessões tutoriais acerca das patologias da linguagem, e que fundamentavam processos de avaliação e terapia fonoaudiológica de tais patologias. Nas duas horas seguintes, abria-se espaço para a prática, de modo que o aluno se engajava em atividades i) de avaliação de gravações de áudios e vídeos de interações das quais participavam crianças com alterações de linguagem, com levantamento de hipóteses diagnósticas, ii) de elaboração de materiais e instrumentos para serem utilizados em avaliações e terapias de alterações da linguagem, e iii) de planejamento terapêutico, a partir de resumos de casos clínicos que eram passados para eles.

As práticas de habilidades podem ser consideradas o momento do PBL em que as atividades mais se aproximam daquelas desenvolvidas no modelo tradicional; todavia, não obstante tal similaridade, tais práticas não deixam de proporcionar situações que requer engajamento ativo da parte dos alunos. Ademais, devido ao fato de os alunos serem divididos em pequenos grupos, o professor se encontra mais próximo aos alunos, o que favorece sua intervenção em termos de auxiliar os alunos no desenvolvimento de suas habilidades práticas, primando sempre por apenas sinalizar o caminho para que os alunos tomem suas decisões.

Durante os encontros, assim como nas sessões tutoriais, aconteciam avaliações, no caso, do tipo avaliação formativa, em que há um feedback constante do professor acerca do desempenho do aluno nas atividades propostas, bem como dos alunos acerca dos seus próprios desempenhos (autoavaliação) e dos alunos acerca do desempenho dos seus colegas de grupo (avaliação interpares). Os pontos de avaliação referiam-se ao envolvimento do aluno com o grupo e com as atividades, às características pessoais que 
favorecem o bom desempenho profissional, além de outros aspectos. Além da avaliação formativa, há a avaliação prática, em que foram realizadas atividades que contemplavam estudos de caso a respeito das diferentes patologias da linguagem oral e escrita da criança e do adolescente, para que o aluno pudesse demonstrar sua capacidade crítica com relação à avaliação, ao diagnóstico e ao processo terapêutico em linguagem. Por fim, também se realizava o que se denomina avaliação cognitiva escrita, em que, neste caso, elaboramos questões de múltipla escolha e questões subjetivas, que serviam como uma forma de o aluno demonstrar os resultados do estudo dirigido individual.

Os encontros de habilidades foram proveitosos, pois os alunos traziam as dúvidas que ainda restavam dos tutoriais para serem discutidas, além de juntarem a teoria com a prática. Porém, como a área de linguagem é bastante complexa, os alunos tiveram muitas dificuldades, e um dos motivos para tais dificuldades pode estar relacionado ao pouco tempo para discutir assuntos que no ensino tradicional levariam de um semestre a um ano para serem concluídos; mas, por conta da estruturação da metodologia, os assuntos voltavam a ser abordados em outros momentos, fazendo com que a aprendizagem ocorresse em diversas situações.

De maneira geral, os alunos mostraram-se bastante receptivos às propostas dos encontros de habilidades, pois além de terem a possibilidade de retornar à teoria, puderam observar o que acontece na prática dos atendimentos em linguagem, e tiveram a oportunidade de utilizarem a criatividade para a elaboração de materiais e instrumentos que vão servir para a sua própria prática clínica, tanto para avaliar quanto para intervir nas alterações de linguagem. Essas práticas têm sido muito interessantes e se mostrado essenciais para que o aluno faça a relação de como aquele jogo, brinquedo e/ou material estarão contribuindo para o planejamento e conduta do tratamento.

Podemos considerar que a máxima da efetividade do PBL é aprender a aprender. De modo a atender tal máxima, o aluno deve estar bastante atento e sempre buscando (e se abrindo a) aprender a aprender, pois os bons resultados desse processo de aprendizagem dependem do estudo e da busca incessante pelo conhecimento.

\section{3) Práticas de Ensino na Comunidade}

A subunidade denominada Prática de Ensino na Comunidade (PEC), no período correspondente a este relato de experiência, ocorreu em creches e escolas da prefeitura municipal de Lagarto e consistia em práticas relacionadas à linguagem. A fim de possibilitar ao leitor conhecer o cenário onde práticas em linguagem eram realizadas, iremos descrever as creches que participavam do empreendimento de PEC de acordo com os seguintes critérios: i) caracterização; ii) estrutura e organização; iii) recursos materiais; iv) equipe técnica e corpo docente; e v) participação da família. É importante ressaltar que tais descrições compreendem tentativas de delinear, em linhas gerais, o que 
poderíamos considerar serem os aspectos/perfis significativamente primários das instituições participantes.

As creches e escolas envolvidas nessa modalidade de atividade (PEC) são caracterizadas por instituições de natureza pública (municipais), que acolhem crianças de seis meses a sete anos, com horários diurnos de funcionamento, sendo a duração dos turnos da manhã e da tarde em torno de quatro horas para cada turno. No que diz respeito às práticas dos alunos de fonoaudiologia nessas instituições, estas ocorriam no turno da tarde, às quartas-feiras ou às quintas-feiras, com quatro horas de duração.

Ao longo da nossa inserção nessas creches e escolas, pudemos observar que as condições de limpeza e higiene, em algumas creches, eram satisfatórias, e em outras, nem tanto. Quanto à disponibilidade de materiais didáticos e pedagógicos, esta não podia ser considerada satisfatória/suficiente na grande maioria das creches. Lidando habilidosamente com toda a escassez de recursos, encontrava-se uma equipe técnica, constituída por profissionais que cuidavam da limpeza das escolas e creches, da alimentação das crianças, da vigilância, entre outros, bem como professores com curso de magistério e/ou curso superior em pedagogia.

Embora pudéssemos observar que as crianças eram bem assistidas nas escolas e creches, a mesma realidade parecia não ser encontrada em suas casas, uma vez que as famílias, em muitos casos, não se faziam presentes na vida escolar das crianças, negligenciando qualquer tipo de participação nesse âmbito. Quando os alunos de fonoaudiologia se dispuseram a realizar atividades que necessitavam da participação dos pais, foi necessário lançar mão de atrativos, como, por exemplo, lanches e sorteios de brindes para garantir tal participação.

Eram nos cenários acima descritos que aconteciam as práticas em comunidade dos alunos de fonoaudiologia. Tais práticas eram norteadas por ações colaborativas entre nós (mediadoras dos processos de construção de conhecimentos) e os alunos (agentes de toda a aprendizagem). Cabia a nós, professoras, mediar o entendimento dos alunos acerca do papel do fonoaudiólogo no âmbito escolar e, por conseguinte, possibilitar o conhecimento dos limites de atuação desse profissional nas escolas. Por outro lado, cabiam aos alunos vivências de observação e de elaboração de ações de promoção à saúde, prevenção e identificação de patologias da linguagem.

Logo, no que tange às atividades realizadas no período da disciplina Linguagem na Infância e Adolescência, os alunos foram orientados a observar a linguagem oral das crianças e anotar ocorrências de possíveis comprometimentos linguísticos, a fim de, nos estudos individuais, refletirem sobre os frutos das observações, relacionando os conhecimentos construídos com suas vivências. $\mathrm{O}$ retorno que os alunos ofereciam à comunidade se concretizava por meio da elaboração de propostas de atividades realizadas na própria comunidade, com base em tudo o que foi por eles observado.

Os alunos, sob nossa orientação, em um primeiro momento, realizaram observação da linguagem oral das crianças em situações discursivas e interacionais 
criadas por eles em sala de aula e durante o recreio, identificando possíveis distúrbios da linguagem. A partir dos achados, ou seja, de hipóteses diagnósticas por eles levantadas com base em suas observações e anotações, em um segundo momento, elaboraram propostas de atividades, sob nossa orientação e nosso direcionamento. Tais atividades práticas foram desenvolvidas tanto com as crianças (ex.: teatro) quanto com os pais (ex.: palestra e fôlderes) e professores (ex.: palestra e fôlderes), e abordaram questões de prevenção e promoção, voltando o foco da abordagem para os distúrbios da linguagem por eles identificados na unidade escolar.

O resultado positivo das ações dos alunos podia ser verificado, sobretudo, no aprendizado proporcionado às crianças da creche; nos olhares atentos e curiosos, bem como nos diversos questionamentos dos professores durante as palestras; e também no interesse despertado nos pais dos alunos. O caráter ímpar da experiência vivenciada por nós e pelos alunos não obscurecia as dificuldades por nós vivenciadas enquanto desbravadores daquele território (creches e escolas municipais) onde muitos nunca haviam escutado falar da fonoaudiologia. As dificuldades encontradas não estavam relacionadas à metodologia em si, mas sim a fatores socioculturais e psicossociais que se impunham às práticas na comunidade; situação esta já esperada de ser encontrada na realidade das escolas públicas brasileiras.

Faz-se necessário destacar que atividades de PEC, subsidiadas pelos estudos teóricos propiciados pelos encontros dos grupos tutoriais e pela capacitação possibilitada pelas atividades de habilidades, favoreceram uma capacitação reflexiva e crítica dos alunos, o que irá contribuir para uma formação profissional de ótima qualidade, que conjuga saberes advindos tanto da prática quanto da literatura fonoaudiológica. Ademais, o PBL tem favorecido o desenvolvimento da autonomia dos alunos (interessados e dedicados) também nas PECs.

\section{Considerações finais}

Neste relato, buscamos compartilhar com o leitor nossas experiências de docência com a metodologia PBL, com a pretensão de proporcionar um entendimento de como esta metodologia funciona na prática, ou melhor, nos contextos institucionais da sala de aula e dos diferentes campos de atuação (neste caso, creches e escolas).

A nosso ver, com base em nossas vivências de iniciantes, o PBL, se aplicado fidedignamente por professores e encarado com seriedade pelos alunos, pode se constituir em uma metodologia de ensino de fonoaudiologia bastante eficiente e vantajosa, em comparação com abordagens instrucionais expositivas. Apesar de agregar certo grau de imprevisibilidade e aumentar o tempo de dedicação (tanto dos alunos como dos professores), o PBL parece, de fato, contribuir sobremaneira para a formação de fonoaudiólogos autônomos, bem como seguros de suas práticas clínicas, devido à imersão precoce no contexto da prática. 
O modo como o PBL se estrutura permitiu a construção de uma aprendizagem relacionada à linguagem consideravelmente eficiente (no caso daqueles alunos que se dedicaram honestamente ao estudo e às atividades práticas), que se pautava em uma formação crítico-reflexiva. Os conteúdos da linguagem ganhavam contornos circulares, atrelando-se a realidades que os alunos viam e sentiam. Por outro lado, não há como negligenciar o fato de que, em muitos momentos, palestras expositivas oferecidas aos alunos funcionavam como "tábuas de salvação" para nós, professoras, que nos sentíamos aflitas diante de tantos assuntos complexos a serem abordados e interrelacionados na disciplina em questão. A conclusão a qual chegamos é que, em se tratando do estudo da linguagem e suas patologias, os alunos são indubitavelmente favorecidos pelo hibridismo de palestras expositivas e de sessões mediadas.

Em suma, talvez, a maior vantagem do PBL seja o desenvolvimento da autonomia, estimulada por um despertar da criatividade dos alunos, que, por sua vez, era convidada a comparecer a todo o momento, uma vez que o que estava em pauta eram resoluções de problemáticas, sejam teóricas (nas sessões tutoriais) ou práticas (nas práticas de habilidades e nas práticas de ensino na comunidade).

\section{Referências Bibliográficas}

BARROWS, H. S. "Problem-based learning in medicine and beyond: a brief overview". In: WILKERSON, L.; GIJSELAERS, W. H. (Eds.). Bringing problem-based learning to higher education: theory and practice. San Francisco: Jossey-Bass, 1996. p. 3-12.

FOUCAULT, M. The History of Sexuality. New York: Pantheon, 1978.

LIPKIN, M. "Toward the education of doctors who care for the needs of the people: innovative approaches in medical education". In: SCHMIDT et al. (Eds.). New directions for medical education. New York: Springer-Verlag, 1989. p. 3-16.

MARGETSON, D. "Why is problem-based learning a challenge?". In: BOUD, D.; FELETTI, G. (Eds.). The challenge of problem-based learning. London: Kogan Page, 1999. p. 36-44.

RIBEIRO, L. R. C. Aprendizagem Baseada em Problemas - Uma experiência no ensino superior. São Carlos: EdUFSCar, 2010.

SAVIN-BADEN, M. Problem-based learning in higher education: untold stories. London: Open University Press, 2000. 